\title{
Study of multiple draw-zone interaction in block caving mines by means of a large 3D physical model
}

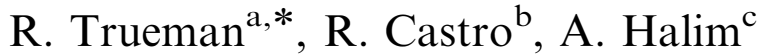 \\ ${ }^{a}$ University of Queensland, Brisbane, Qld 4068, Australia \\ ${ }^{\mathrm{b}}$ University of Chile, Santiago, Chile (formerly University of Queensland) \\ ${ }^{\mathrm{c}}$ Anglo Coal Australia, Australia (formerly University of Queensland)
}

Received 26 July 2007; received in revised form 7 November 2007; accepted 7 November 2007

Available online 20 February 2008

\begin{abstract}
Current production level design guidelines in block caving mines are based on the concept of interaction of movement zones and the spacing of draw-points at which mass flow is achieved. The limit of the isolated movement zone (IMZ) interaction has been determined by observations of the flow of sand and finely fragmented caved rock. This paper presents a study of the mechanisms and limit of IMZ interaction in coarse fragmented caved rock using a large 3D physical model. Results showed that when drawing from multiple drawpoints, the unmoved zone between IMZs is characterised by an increase in vertical load and a decrease in horizontal load. However, it was observed that the unmoved zones between the movement zones of adjacent draw-points did not enter the flow zone, despite drawpoints being spaced at less than 1.2 times the width of the IMZ. This result is in marked contrast to previous findings obtained in sand models, where movement zones have been observed to interact at draw-point spacings up to 1.5 times the width of the IMZ. The major reasons for the differences between the two different model results was found to be that significant stress arching and less induced vertical stress during flow was observed in the gravel model, in contrast to limited stress arching and more induced vertical stress in the sand models. It is hypothesised that significant stress arching would occur in block caving mines, and therefore that the results obtained in the gravel model maybe more representative of full-scale conditions. Movement zones in block caving mines may therefore not interact at draw-point spacings greater than the width of the isolated movement zone.
\end{abstract}

(C) 2007 Elsevier Ltd. All rights reserved.

Keywords: Gravity flow mechanisms; Cohesionless granular materials; Block caving; Draw-point spacing; Stresses

\section{Introduction}

In large scale underground metalliferous mining methods, and in particular in block caving mining methods, the characteristics of gravity flow of broken ore and waste rock, in addition to draw management practices, control the amount of valuable material recovered and the extent to which it is diluted by waste rock. Thus, gravity flow characteristics influence engineering design such as the extraction level layout, in particular the spacing and location of draw-points, and draw-control practices [1].

Current design guidelines for estimating optimal production level layout and best draw-control practices are based

\footnotetext{
${ }^{*}$ Corresponding author. Tel.: + 61733655927 ; fax: + 61733655999.

E-mail address: r.trueman@uq.edu.au (R. Trueman).
}

on the conditions that lead to mass flow or uniform drawdown of the ore waste interface [2,3]. To achieve uniform drawdown, the movement zones which are the disturbed zones due to flow, of individual draw-points must interact. In the literature, there are two schools of thought about what draw-points spacing will lead to uniform drawdown or mass flow. Kvapil [4] and Kvapil et al. [5] have postulated that draw-points should be spaced so that isolated movement zones (IMZs) of adjacent drawpoints overlap. Laubscher [2,3] and others [6-9] have proposed that draw-points can be spaced up to 1.5 times the width of the IMZ if multiple draw-points are drawn from simultaneously. This observation, known as interactive draw, has been derived from experimental observations in three-dimensional (3D) sand models [6-8] and numerical modelling $[9,10]$. It has been postulated that the 
interaction of IMZs at larger distances occurs as a consequence of a re-distribution of stresses in the unmoved zone, which causes its collapse and therefore a lateral expansion and interaction of the movement zones.

Parallel to those studies a different research approach was undertaken at the Colorado School of Mines in the 1980s, where large two-dimensional (2D) models were built to investigate the optimal draw-point spacing considering the width of the isolated extraction zone (IEZ) for different materials $[11,12]$. The IEZ is the zone defining the material that has been extracted by removal of rock at the draw-point at a given mass drawn. Interaction of IEZs was also investigated by Peters [11], who observed that IEZs could interact at spacings of 1.14 times the width of the IEZ. McNearny and Abel [12] carried out investigations on the draw behaviour in block caving using bricks and gravel to simulate the caving and flow processes. They concluded that the shape of the IEZ was an inverted cone having a maximum width at the simulated undercut level. The shape of the IEZ was explained as a consequence of the cantilever effect from the offset between courses of bricks showing that the packing of the discontinuous mass may have an effect on the way that flow zones could develop. Based on observations of the draw behaviour from three adjacent draw-points, they postulated that draw-point spacing should equal the width of the IEZ and that a smaller spacing should be avoided to prevent early dilution. Those studies were conducted in 2D models and the authors appeared not have been aware of the interactive draw theories developed during the same period of time.

The interactive draw theory proposed by Laubscher, and developed more than 20 years ago, is today the most widely used method to define the draw-point spacing in block and panel caving mines (see, for example, Ref. [13]). Block and panel caving have evolved from that time from being applied to low competent rock and low block heights to be now used for a wide range of rock mass competences and block geometries. It is now quite common to exploit coarse fragmented caved rock. In the literature, there is no compelling evidence that the mechanisms of interaction observed in finely fragmented granular materials such as sand can be applied to coarse fragmented rock [2,3]. As part of an international caving study, a large-scale 3D physical model was built to study the flow characteristics of coarse fragmented rock. In a previous paper [14], the authors described the first part of the experimental work, which involved the study of isolated draw mechanisms for block caving. This paper presents the second part of that project, which involved a comprehensive experimental programme aimed at investigating the limit of IMZ's interaction for coarse fragmented caved rock.

\section{Experimental setup}

\subsection{Physical model}

Experiments were carried out in the largest 3D physical model built to date to investigate flow in caving environ- ments (see Fig. 1). In a previous publication, the authors described the methodology used to carry out experiments in this installation [14]. The draw-point dimensions and the height of the model were at a scale of 1:100. The model was filled up to $3300 \mathrm{~mm}$; this represented a scaled column height of $330 \mathrm{~m}$. The total base of the model had dimensions of $2390 \times 2750 \mathrm{~mm}$, representing an area of $239 \times 275 \mathrm{~m}$.

\subsection{Model assumptions}

The following assumptions and simplifications were made to study the interaction limit for IMZs in block caving through physical modelling: (1) It is assumed that the rock mass has caved. In this context, the rock mass could be considered a granular mass composed of noncohesive and coarse fragments that flow slowly towards the draw-points under the action of gravity. (2) The granular mass is characterised through its size, shape and angle of friction and could be considered heterogenous (composed of large and fine particles) and isotropic. (3) The granular flow occurs in a 3D environment. (4) As particles flow to draw-points, some rock breakage occurs through abrasion but it is negligible. (5) The geometries of the flow zones at different geometrical scales in the large physical model are

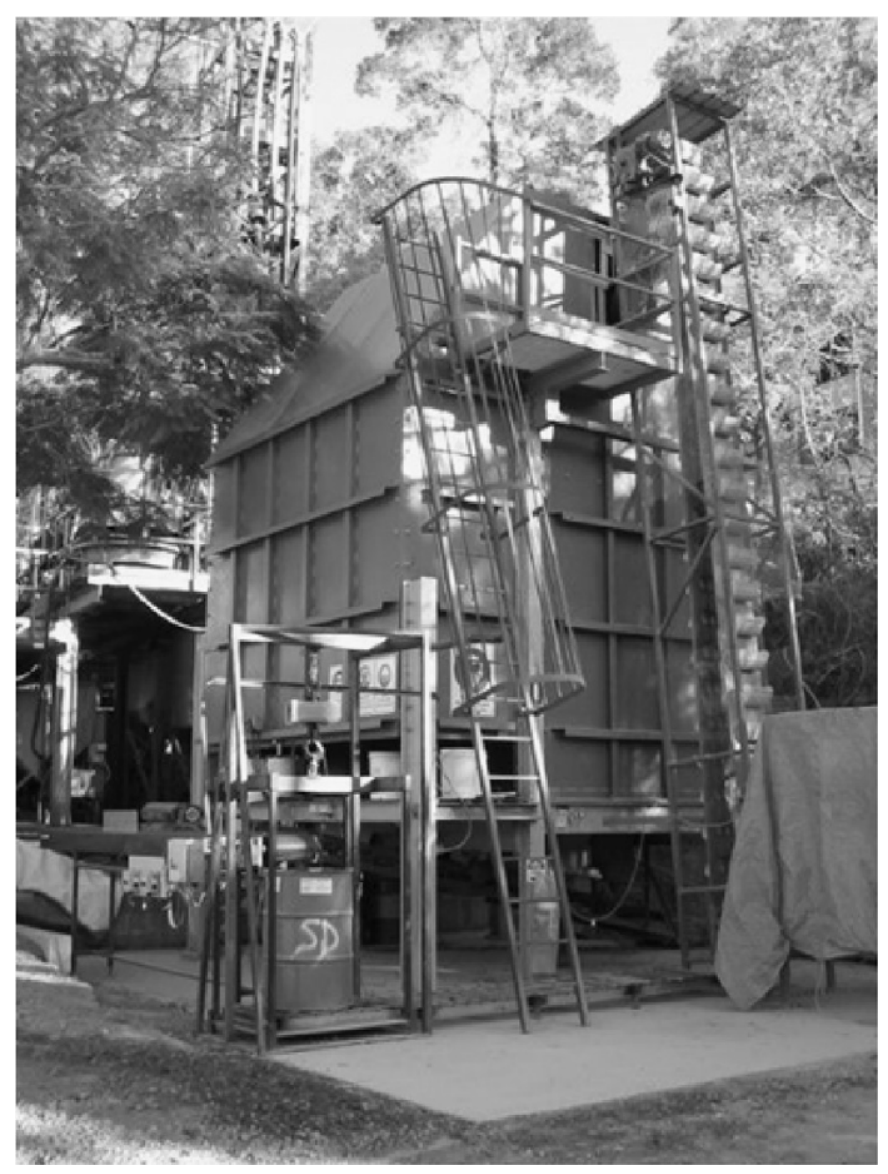

Fig. 1. Large physical model. 
comparable as long as the materials have equal friction angle and particle shape.

\subsection{Materials and instrumentation}

The material used in the experiments was crushed phyllite from a local quarry. The size distribution analysis of the material showed that $86 \%$ of the gravel was within 9.5-6.7 $\mathrm{mm}$ passing size, meaning a narrow distribution around a mean size of $8 \mathrm{~mm}$. This represents a mean scaled size of $800 \mathrm{~mm}$ and therefore simulates relatively coarse fragmentation. The effect of scale on model results has been discussed in a previous paper [14]. No scale distortion was observed between scales of 1:30 and 1:100. In these tests, we did not intend to scale a particular size distribution, as previous experiments conducted in the same installation demonstrated that particle size distribution had a negligible effect on the IMZ geometry. The internal friction angle of the gravel was obtained from tests using a large shear test box. The material was cohesionless and had a friction angle of $41^{\circ}$ when tested under similar density and stress conditions to those in the model. The model walls were constructed of steel and the wall friction angle was calculated to be $25^{\circ}$ [15].

Measurement of extraction and movement envelopes in 3D and stresses were undertaken. Extraction zones were measured through the back analysis of recovered labelled markers. Movement zones in 3D were obtained through the use of purposely designed movement sensors, which were a modified extensometer, which would trigger as the material started to move inside the model [14]. The stresses developed during loading and flowing of gravel inside the bin were obtained through load cells located in the model base and walls. In the experiments, up to 10 load cells were located in the floor and walls of the model. Temperature was continuously monitored so that measured stresses were corrected to changes in environmental conditions [15].

\section{Experimental results}

Four experiments were conducted in the large physical model to study the interaction of movement zones when drawing from a large number of draw-points. These experiments were run from January 2005 to March 2006 with each test taking approximately from 2 to 4 months to complete. Additional two experiments were run to gain understanding of the experimental errors when measuring stresses in a granular material.

The first two tests were carried out to obtain a value for the average IMZ's geometry as a function of the mass drawn and the associated experimental errors. In the first test, Experiment $8 \mathrm{~mm}-\mathrm{Tl}$, draw was conducted from a single point of draw. In the second test, Experiment $8 \mathrm{~mm}$-T2, two draw-points spaced at $1200 \mathrm{~mm}$ were drawn concurrently and load cells were located in the model base to determine the vertical stresses around the isolated flow zone. At this spacing, it was anticipated that the IMZ of each draw-point would act in isolation.

Two large experiments were carried out to study the interaction limit for multiple movement zones. In the third test, Experiment $8 \mathrm{~mm}$-T3, nine draw-points spaced 780-mm apart in a triangular configuration were drawn concurrently. The reason for using a triangular layout was so that draw-points were equally spaced in all directions. In concurrent draw, material is removed in small amounts and evenly from all draw-points intending to simulate in the scaled model an ideal draw scenario using a load haul dump ore extraction system. Load cells were located between draw-points to determine the vertical stresses at the model simulated production level during flow. A plan view with the location of draw-points and load cells is presented in Fig. 2a. In the second large test, Experiment $8 \mathrm{~mm}-\mathrm{T4}, 13$ draw-points in a 480-mm triangular layout were drawn concurrently. Load cells were located between draw-points in order to investigate the effect of the close spacing on loads measured at the model base. Load cells to measure the confinement within the model were installed in the model walls (see Fig. 2b).

\subsection{Isolated draw zones}

We needed first to obtain the average width of the IMZ and its experimental error in order to calculate the spacing of draw-points at which interaction of IMZs would occur. Fig. 3 shows the mean value of the IMZ as a function of the IMZ's height. It was observed that the width of the IMZ increases with the height and mass draw and does not reach a limit. The rate, at which the width of the IMZ increases with height, decreases during draw. These findings are similar to those reported in a previous publication on isolated draw [14].

The experimental error to determine the IMZ's width was obtained from three tests. The standard error for the IMZ width was calculated to be $22.8 \mathrm{~mm}$. That means that if the IMZ's widths are normally distributed around the mean, at $95 \%$ confidence it is expected that any value ranging between $\pm 4.6 \mathrm{~mm}$ from the mean at a given height could be obtained. In that context, this test showed that draw-point spacings above 1.1 IMZ's width could be used to test the limits of interaction.

\subsection{Interaction tests}

In the first multiple draw-point test, nine draw-points were drawn concurrently. Draw-points were spaced at $740 \mathrm{~mm}$ corresponding to a spacing of 1.2 times the mean width of the IMZ at the full height of draw. During the test, approximately $3 \mathrm{~kg}$ of material were drawn from a single draw-point before moving to the next draw-point and so on until the IMZ movement zones of all nine drawpoints had reached the surface. Experimental results showed that movement zones did not increase to the extent that mass flow occurred. Fig. 4 shows a vertical section of 

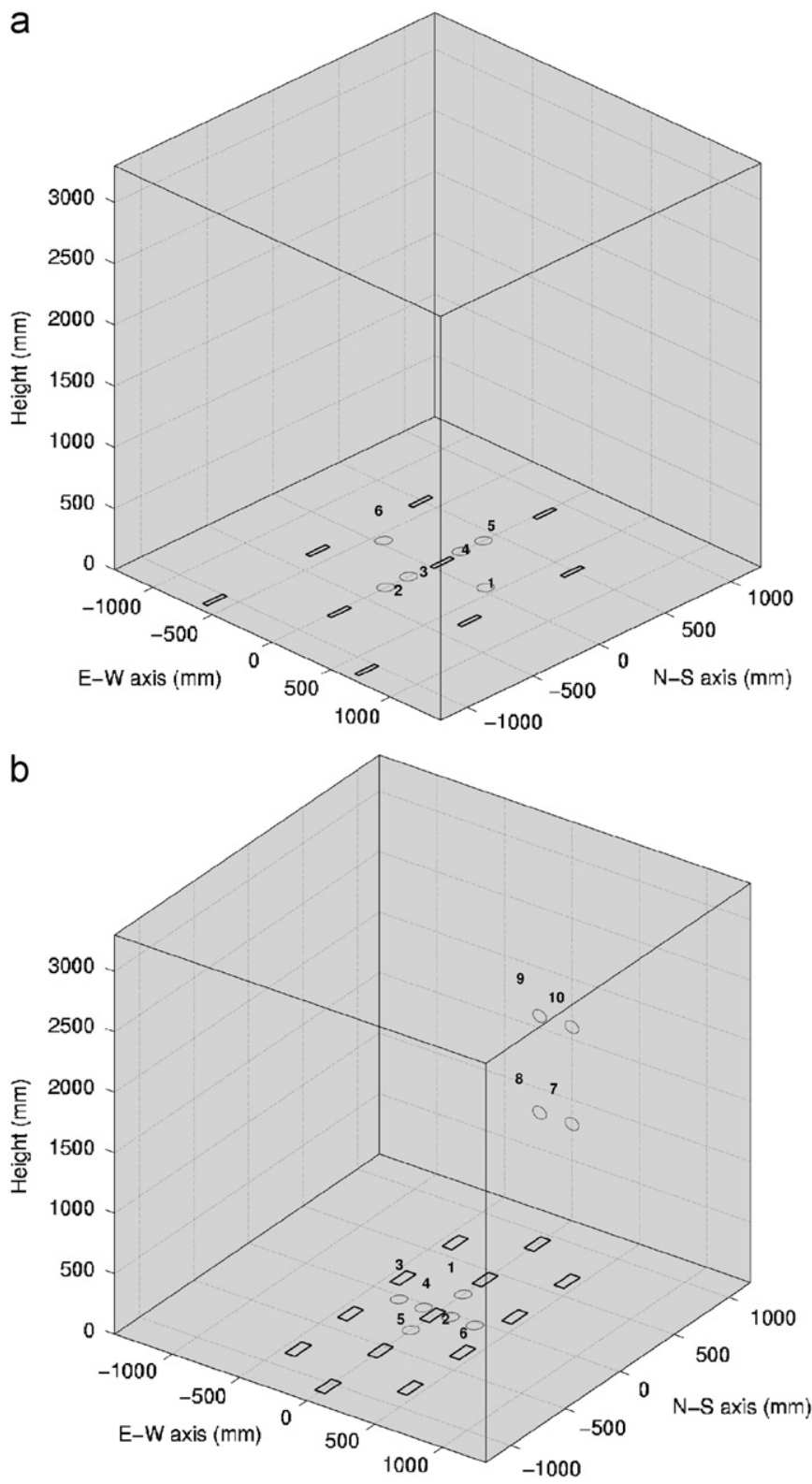

Fig. 2. 3D scheme of draw-point and load cell location used during interactive draw tests: (a) experiment $8 \mathrm{~mm}$-T3, (b) experiment $8 \mathrm{~mm}$-T4.

the movement zones through the $\mathrm{N}-\mathrm{S}$ axis in Fig. 2a which were obtained using the movement sensors. Results from movement sensors were corroborated by measurements of the surface profile so that a digital representation was obtained by linear interpolation of different depths. At the surface, it was evident that mass flow did not occur as visible humps between the craters of the draw zones were observed (Fig. 5).

Given that in the interactive draw experiment the unmoved material between IMZs was not mobilised due to concurrent draw, a second experiment was planned. In the second multiple draw-point test, a total of 13 drawpoints were drawn concurrently. Draw-points were spaced at $480 \mathrm{~mm}$ corresponding to a spacing of 1.2 times the mean width of the IMZ at a height of $1700 \mathrm{~mm}$ from the model base. In this experiment, the same draw practice was adhered to as in the previous interaction experiment. This test aimed to study interaction but when the unmoved material was under an overburden of $1600 \mathrm{~mm}$. This setup allowed us to study the conditions that lead to the uniform drawdown of the ore/waste interface. At this spacing, flow zones will nominally overlap when the IMZs reach a height of about $2200 \mathrm{~mm}$ even if no expansion of movement zones occurs.

Fig. 6 shows vertical planes of the movement zones for five draw-points passing through the $\mathrm{N}-\mathrm{S}$ axis in Fig. $2 \mathrm{~b}$ after approximately $80 \mathrm{~kg}$ had been drawn per draw-point. At this stage of draw, the tips of the movement zones had reached a height of about $2200 \mathrm{~mm}$. The movement zones remained isolated. The average width of the IMZs was at this stage $412 \mathrm{~mm}$ (S.D. $28 \mathrm{~mm}$ ); i.e., $1.18 \times$ draw-point spacing.

Fig. 7 illustrates the IMZ widths up to a mass drawn of $90 \mathrm{~kg}$ from each draw-point for the five draw-points shown in Fig. 6. The average and 95\% confidence interval for the IMZ measured previously are included in the graph for comparison. It can be observed that the measured movement zone widths for this experiment are either the average values measured in isolated draw experiments or below the average width. The draw-point spacing at $90 \mathrm{~kg}$ drawn was between 0.88 and 1.14 times the width of the individual movement zones measured in this experiment. There was no evidence of any expansion of movement zones.

The IMZs started to come together after approximately $90 \mathrm{~kg}$ had been drawn per draw-point. At this mass drawn, the distance between draw-points was equal to the average IMZ, i.e., $480 \mathrm{~mm}$. Movement sensors located at the $2600 \mathrm{~mm}$ level triggered within a short mass drawn interval, some while extracting draw-points not immediately below them. This indicated that uniform drawdown or mass flow had been initiated. Measurements of subsidence after the IMZs had reached the surface confirmed that. This illustrates that uniform draw down is achieved in the gravel model only at a draw-point spacing of less or equal to the IMZ's width at a given height of draw.

\section{Stresses in the granular media}

It was considered that the differences in the results obtained in our gravel model when compared to sand models may be explained by a consideration of the stresses in the granular medias.

Vertical stresses and a limited number of horizontal stresses were measured both during filling of the gravel model and during draw; see Ref. [15] for a full description of the location of load cells and results. After filling the model, the average vertical stress on the load cells that were located on the base of the model was about $72 \%$ of the overburden weight (S.D. 0.33), indicating that vertical stress was transferred to the walls of the model through stress arching [15]. As noted by Janssen (as described in 


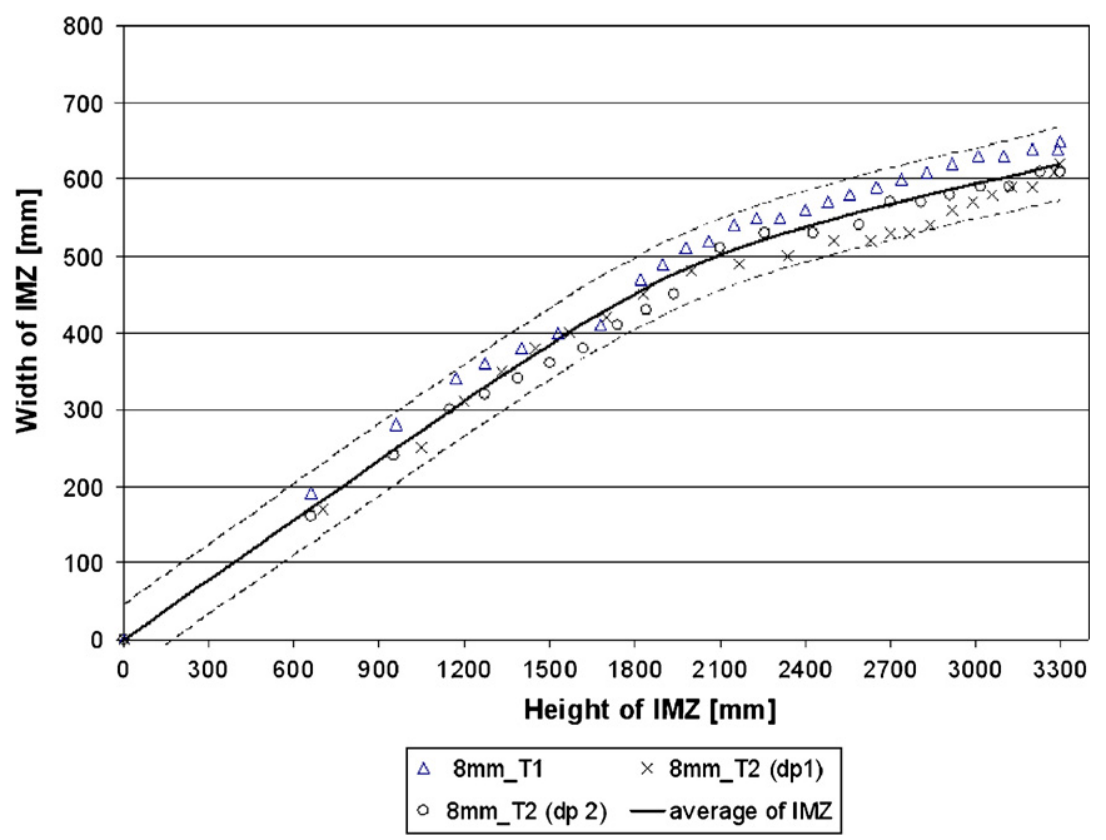

Fig. 3. IMZ width as function of the height. The average IMZ and the $95 \%$ confidence bound have been included.

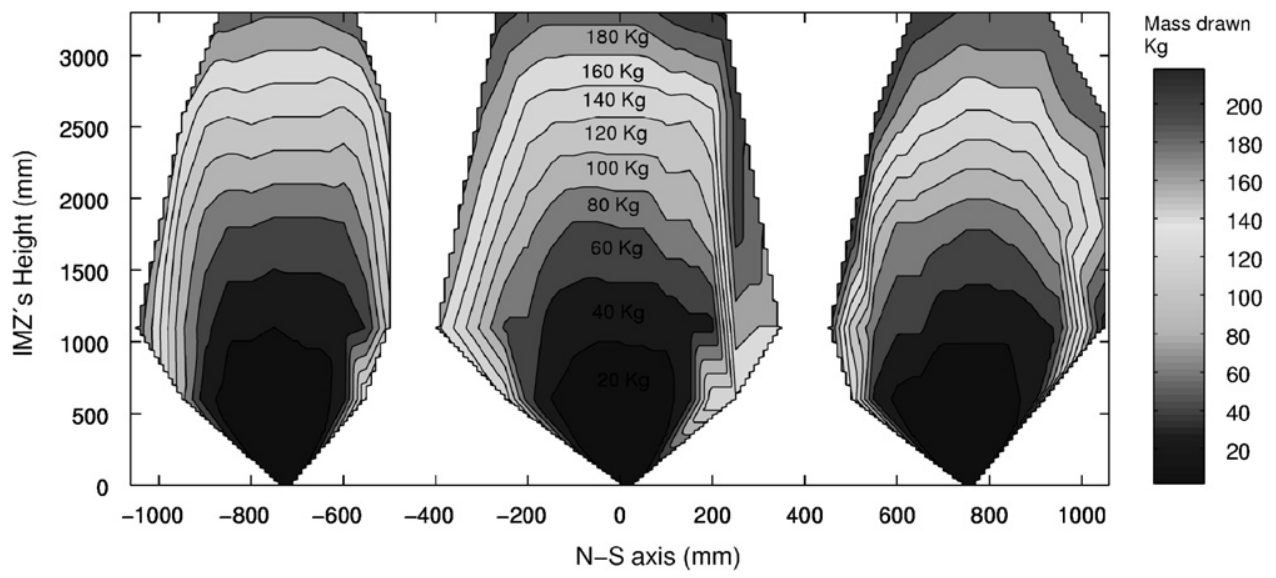

Fig. 4. Section of the movement zones through the $\mathrm{N}-\mathrm{S}$ section at different stages of draw up to the movement zones intersecting the surface for concurrent draw.

Nedderman [16]) as early as the 1890 s, stress arching is a feature that has been observed when granular materials are contained in a reservoir and it has been explained in terms of shear forces developed at the container boundaries.

During the drawing process, it was observed that vertical stresses between flowing zones increased as the IMZ's widths approached the position of the cell [15]. The peak vertical stress measured in the unmoved material reached an average value of about 1.3 times the initial vertical stress (S.D. $=0.11)$, when the distance between the centroids of the flow zones were about 1.4 times the width of the IMZ. Horizontal stresses also varied with the position of the IMZ, being maximum at the tip of the IMZ and reaching a minimum at approximately half way its height. From the horizontal and vertical stress data along with the shear strength properties of the granular media, it was postulated that induced stress during flow was not causing shear failure of the material in the unmoved zones. Review of past research work carried out in sand models was necessary in order to explain the differences in experimental findings regarding the interaction limit.

Load cell measurements were not reported by Marano [6] for his sand model experiments. However, researchers that carried out similar experiments to Marano in sand models in Chile and achieved similar results kindly facilitated to the authors their load cell measurements for further analysis [15]. This allowed comparisons between stresses in sand models and our gravel model. A review of the measurements suggests that the stress state of both models were not similar [15]. In the sand model, arching did not occur after filling of the model and initial vertical stresses were close to overburden weight. This is probably 
a

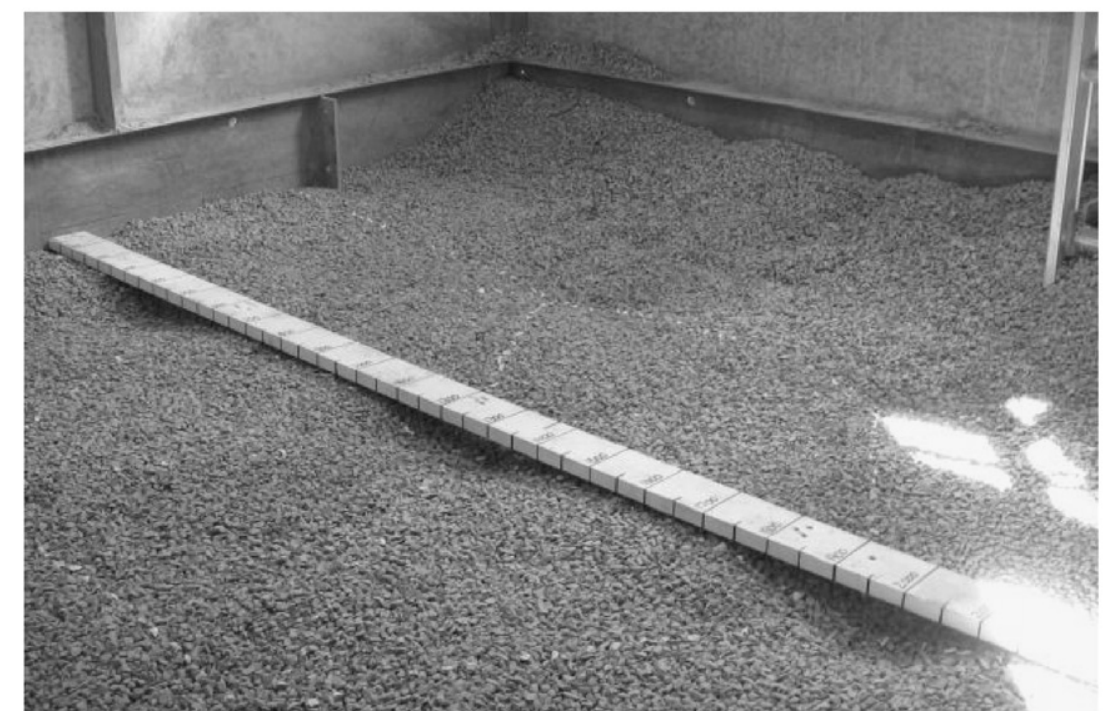

b

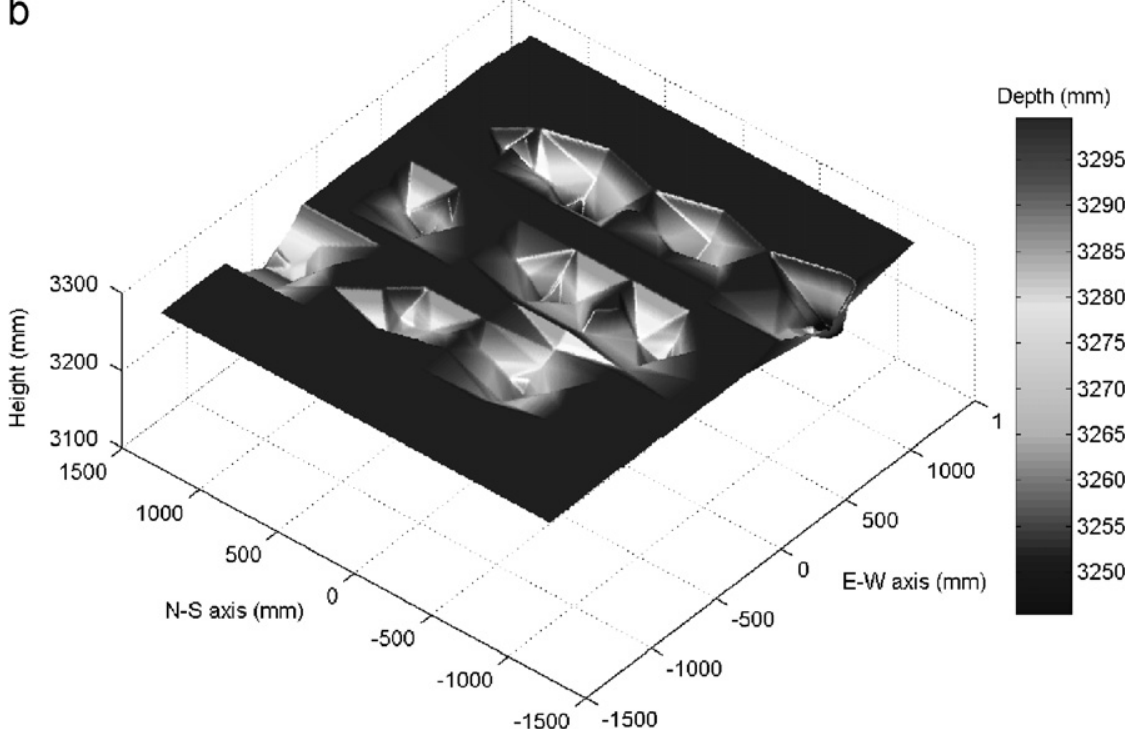

Fig. 5. Photograph (left) and 3D geometry (right) of the model surface after the surface breakthrough of the IMZs of all draw-points.

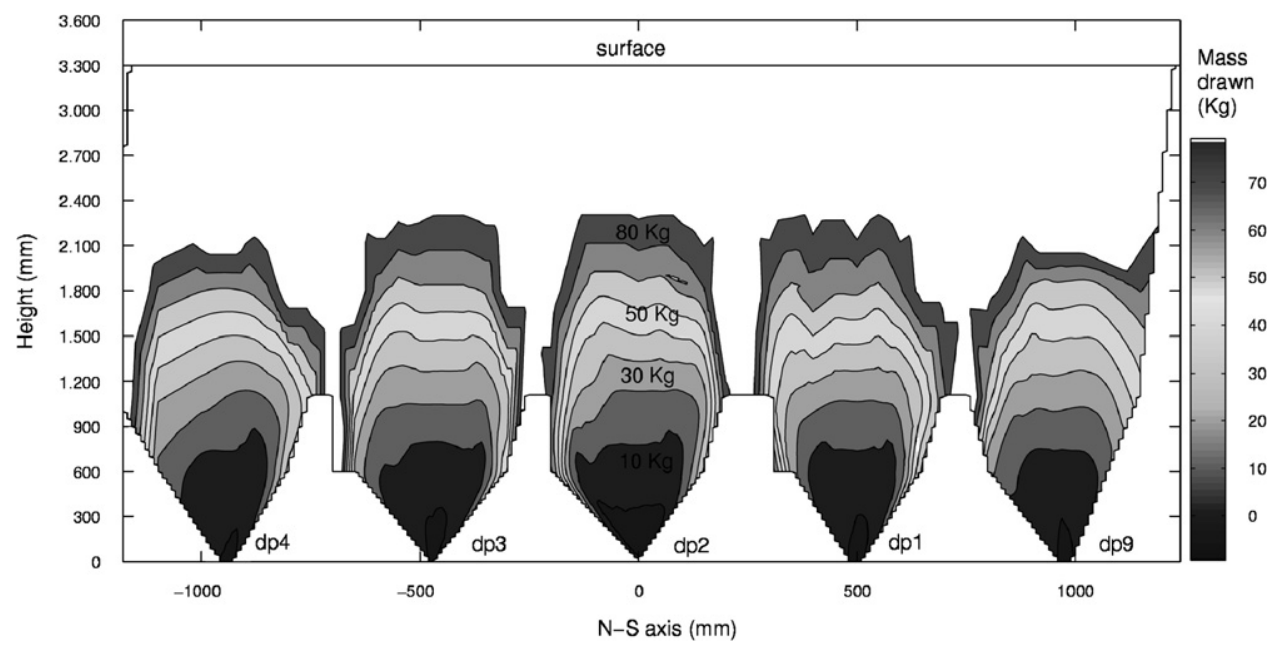

Fig. 6. Vertical section of IMZ for experiment $8 \mathrm{~mm}$-T4 at different mass drawn. 


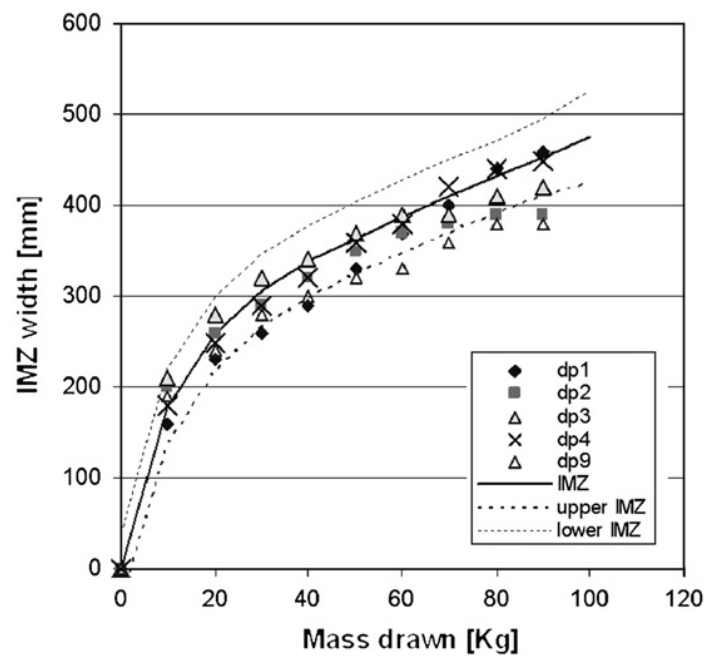

Fig. 7. Comparison between isolated movement zone at $95 \%$ prediction bound and those obtained in the multiple draw-point interactive test.

due to the use of a very low friction wall (plexiglass) in the sand models. Shear forces would have been close to zero and therefore most of the material weight was transferred to the base of the model. During draw, induced peak stresses in the unmoved material between draw-points in the sand model experiments were on average about 1.9 times the initial load, well above the average peak values of about 1.3 measured in the gravel model. The relatively larger initial and induced vertical stress state in the sand model experiments in conjunction with the testing of a weaker material under shear $\left(35^{\circ}\right.$ for sand vs $41^{\circ}$ for gravel in our tests) presumably induced the collapse of unmoved material between the IMZs in the sand model experiments.

\section{Discussion and conclusions}

In our experiments, collapse of unmoved zones between flowing zones did not occur if the distance between drawpoints were larger than the width of the IMZ. Although the load cells showed an increase in vertical load between the IMZs and a decrease in horizontal loads, this was not enough to induce collapse of the unmoved material.

Load cell measurements from the original sand model experiments where expansion of movement zones during the drawing of multiple draw-points was first observed were not published. Similar sand model experiments that included load cell measurements were later carried out in Chile that confirmed the expansion of movement zones. We obtained the load cell results from these experiments and this allowed comparisons between stresses in sand models and our gravel model. A review of the measurements suggests that the stress state of both models were not similar. In the sand model, arching did not occur and initial vertical stresses measured at the base of the model were close to the overburden weight. This was probably due to the use of a very low friction wall (plexiglass) in the sand models. During draw, average induced peak stresses in the sand model experiments were significantly above the average measured in the gravel model. The relatively larger initial and induced vertical stress state in the sand model experiments in conjunction with the fact that the shear strength of sand is less than that of gravel is the probable reason for the differences between the two model results.

The quantitative evidence that movement zones expand during draw from multiple draw-points appears to be largely derived from sand models and numerical models. The use of a very low friction angle boundary condition that inhibits stress arching in the sand models may be the reason that this occurred. Pierce [10] has postulated that the numerical models that have been used to simulate collapse of movement zones may also be underestimating stress arching. Expansion of the zone of extraction was measured in a large 2D gravel model at the Colorado School of Mines but at a draw-point spacing of only 1.14 times the width of the extraction zone. Castro [15] measured dispersions between the widths of IEZs of this order by repeating the same experiment multiple times. The observation in the Colorado School of Mines experiments is therefore likely to be the result of the dispersion of the measurements of the extraction zone for identical experiments. The dispersion was not measured in the Colorado School of Mines experiments. Laubscher [2,3] mentions that the expansion of movement zones during the draw of multiple draw-points was backed up with observations in caving mines but presented no quantitative data. Without a significant amount of instrumentation it would be difficult to be quantitatively sure of this observation. There is no evidence of the use of instrumentation to measure movement zones in caving mines.

In a real block caving situation, the flow of broken rock would occur with a boundary that would have a relatively high friction angle. Rough walls would result in more stress arching than even the values measured in the gravel physical model. In that context, it is postulated that the gravel model may be a more accurate representation of the flow of broken rock in a block caving situation than the sand models used to date to study movement zone interaction. Movement zones in block caving mines may therefore not interact at draw-point spacings greater than the width of the IMZ.

\section{Acknowledgements}

The paper describes a component of work carried out within the Mass Mining Technology Project (MMT) run through the University of Queensland's Sustainable Minerals Institute, Brisbane, Australia. Sponsors of the MMT include: BHP Billiton, CODELCO, DeBeers, LKAB, Newcrest Mining, Orica, Rio Tinto, and Sandvik Tamrock. Their support and recommendations for the direction taken in the MMT Gravity Flow research are appreciated. The authors are also grateful to Gideon Chitombo and Geoffrey Just of the University of 
Queensland, and Matt Pierce from Itasca Consulting Group, for their contributions throughout the research.

\section{References}

[1] Brown ET. Block caving geomechanics. Brisbane: Julius Kruttschnitt Minerals Research Centre, The University of Queensland; 2003.

[2] Laubscher D. Cave mining - the state of the art. J South Afr Inst Min Metall 1994;94:279-93.

[3] Laubscher D. Block caving manual. Report prepared for the international caving study. Brisbane: JKMRC and Itasca Consulting Group; 2000.

[4] Kvapil R. Gravity flow of granular materials in hoppers and bins. Int J Rock Mech Min Sci 1965;2:35-41.

[5] Kvapil R, Baeza L, Rosenthal J, Flores G. Block caving at El Teniente mine, Chile. Trans Inst Min Metall A 1989;98:43-56.

[6] Marano G. The interaction between adjacent draw points in free flowing materials and it application to mining. Chamber Mines J 1980;22:25-32.

[7] Susaeta A. Theory of gravity flow (part 1). In: Proceedings of Massmin 2004, Santiago, Chile, 2004. p. 167-72.
[8] Susaeta A, Díaz H. Estado del arte del modelamiento del flujo gravitacional en minería por hundimiento de bloques. Minerales 2000;55:17-26.

[9] Verdugo R, Ubilla J. Geotechnical analysis of gravity flow during block caving. In: Proceedings of Massmin 2004, Santiago, Chile, 2004. p. 195-200.

[10] Pierce M. Itasca Consulting Group. Personal communication, 2006.

[11] Peters D. Physical modelling of the draw behaviour of broken rock in caving. Quart Col Sch Mines 1984;79:1-48.

[12] McNearny RL, Abel JF. Large-scale two-dimensional block caving model tests. Int J Rock Mech Min Sci 1993;30:93-109.

[13] Chacon J, Gopfert H, Ovalle A. Thirty years evolution of block caving in Chile. In: Proceedings of MassMin 2004, Santiago, Chile, 2004. p. 387-92.

[14] Castro R, Trueman R, Halim A. A study of isolated draw zones in block caving mines by means of a large $3 \mathrm{D}$ physical model. Int $\mathbf{J}$ Rock Mech Min Sci 2007;44:860-70.

[15] Castro R. Study of the mechanisms of granular flow for block caving. $\mathrm{PhD}$ thesis. University of Queensland, 2006.

[16] Nedderman RM. Statics and kinematics of granular materials. Cambridge: Cambridge University Press; 1992. 